\title{
Acute limb ischemia caused by incorrect deployment of a clip-based arterial closure device
}

\author{
Łukasz Dzieciuchowicz, Maciej Zmysłowski, Karolina Stefaniak, Grzegorz Oszkinis \\ Department of General and Vascular Surgery, Poznan University of Medical Sciences, Poznan, Poland
}

Videosurgery Miniinv 2016; 11 (2): 111-114

DOI: $10.5114 /$ wiitm.2016.59577

\begin{abstract}
Failure of a vascular closure device most commonly results in a hemorrhage or pseudoaneurysm formation. In this paper a rare case of severe acute limb ischemia following incorrect deployment of a clip-based closure device (Starclose $S E$, Abbott Vascular) in a 31-year-old woman is presented. Symptoms of acute limb ischemia occurred at the start of the ambulation, $6 \mathrm{~h}$ after completion of the procedure. Because of the severity of ischemia the patient was treated surgically, and limb perfusion was successfully restored. An attempt of closure of an inadvertently punctured narrow superficial femoral artery was identified as the cause of this complication.
\end{abstract}

Key words: vascular injury, endovascular treatment, femoral artery injuries, peripheral arterial catheterization.

\section{Introduction}

Vascular closure devices have been shown to reduce time to hemostasis, ambulation and hospital discharge when compared to manual compression [1]. Also some benefit in short-term quality of life has been demonstrated. However, when they fail, the number of vascular complications increases. Vascular closure device failure most commonly leads to hemorrhagic complications, whereas occlusive complications are the least common [2]. In this paper a case of severe acute limb ischemia following the incorrect use of a clip-based closure device (Starclose SE, Abbott Vascular) is presented.

\section{Case report}

A 31-year-old woman was referred to our center from another institution because of acute right lower limb ischemia. Earlier on that day she had undergone the procedure of radiofrequency ablation through a right percutaneous femoral approach due to supraventricular tachycardia. She had a history of an unsuccessful attempt of ablation in the past. The procedure itself was uneventful. The closure of the puncture site by the Starclose device was attempted by the cardiology resident. Despite deployment of the device, bleeding from the puncture site occurred and hemostasis was achieved with a kaolin-impregnated gauze (QuickClot, Z-medica) and compression. Six hours later the compression was relieved and the patient was allowed to ambulate. As soon as she started to walk she experienced a severe pain of her right lower limb. Acute limb ischemia was diagnosed and she was transferred to the Vascular Surgery Department. On admission, she reported severe pain of the right lower extremity. The foot was cold and pale with absence of capillary refilling. Both superficial and deep sensations were abolished. Her height, weight, body surface area and body mass index were $160 \mathrm{~cm}, 55 \mathrm{~kg}, 1.56 \mathrm{~m}^{2}$ and $21.5 \mathrm{~kg} / \mathrm{m}^{2}$, respectively. Computed tomography (CT) angiography demonstrated occlusion of the proximal portion of the su-

\section{Address for correspondence}

Maciej Zmysłowski, Department of General and Vascular Surgery, Poznan University of Medical Sciences, 1/2 Długa St, 61-848 Poznan,

Poland, phone: +48 500798 332, e-mail: zmyslowskimaciej@gmail.com 
perficial femoral artery and occlusion of the popliteal artery and proximal segments of the tibial arteries. At the level of bifurcation of the common femoral artery two metallic objects were seen, one at the anterior wall and the other at the posterior wall of the femoral artery (Photo 1). The diameters of the common femoral artery and superficial femoral artery were 5.5 and $4.5 \mathrm{~mm}$, respectively. Because of the severity of acute limb ischemia, urgent surgery was performed. The femoral artery was exposed in the groin through a longitudinal skin incision. The presence of a well-incorporated clip was noted at the anterolateral aspect of the common femoral artery, and a recent, open puncture hole was seen on the anterior aspect of the superficial femoral artery. Longitudinal arteriotomy was performed. The thrombus at the origin of the superficial femoral artery was found and removed, and protrusion of a polyp-like structure at the posterior wall was demonstrated. This structure was formed by the posterior wall intima grasped by a Starclose clip (Photo 2). The protruding intima together with the clip were excised and the arteriotomy was closed with a saphenous venous patch. Then through a medial approach the popliteal artery was exposed, and it was possible to remove the thrombotic material in one piece from the proximal and distal segment of the artery. Sat-
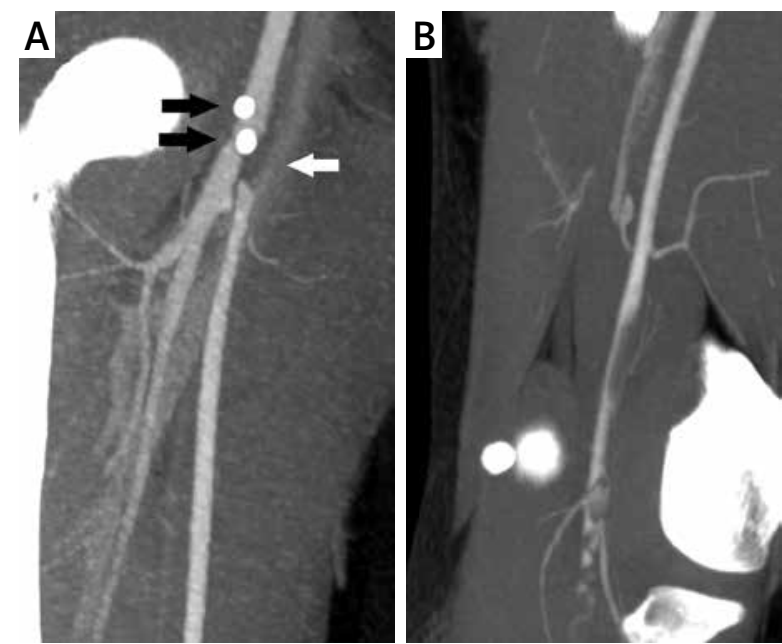

Photo 1. CT angiography showing the occlusion of the superficial femoral artery (white arrow) and the presence of two metallic objects, one at the anterior wall of the common femoral artery and the other at the posterior wall of the superficial femoral artery (black arrows) (A) and occlusion of the popliteal artery (B) isfactory inflow and outflow were achieved and arteriotomy was closed with a saphenous vein patch. The postoperative course was uneventful, and the patient was discharged on the second postoperative day with palpable distal pulses.

\section{Discussion}

This paper presents a very rare case of severe acute limb ischemia caused by a failed attempt of closure of the femoral artery puncture site by a nitinol clip-mediated closure device. In the study of 603 vascular site closures with Starclose only one occlusion $(0.17 \%)$ and one stenosis $(0.17 \%)$ of the common femoral artery were observed [3].

Probably the primary cause of the described complication was the attempt to close the puncture site in a narrow superficial femoral artery. During the second step of deployment of the Starclose device, possible resistance to traction caused by blocking of the locator wing in the narrow lumen of the artery, which additionally may have been in a spasm, and probably also by engagement of the intima, might have been interpreted by the operator as the resistance of the anterior wall to the locator wing, and when the nitinol clip was released it captured the posterior wall. Because of the soft structure of a healthy artery in a young woman, a polyp-like struc-

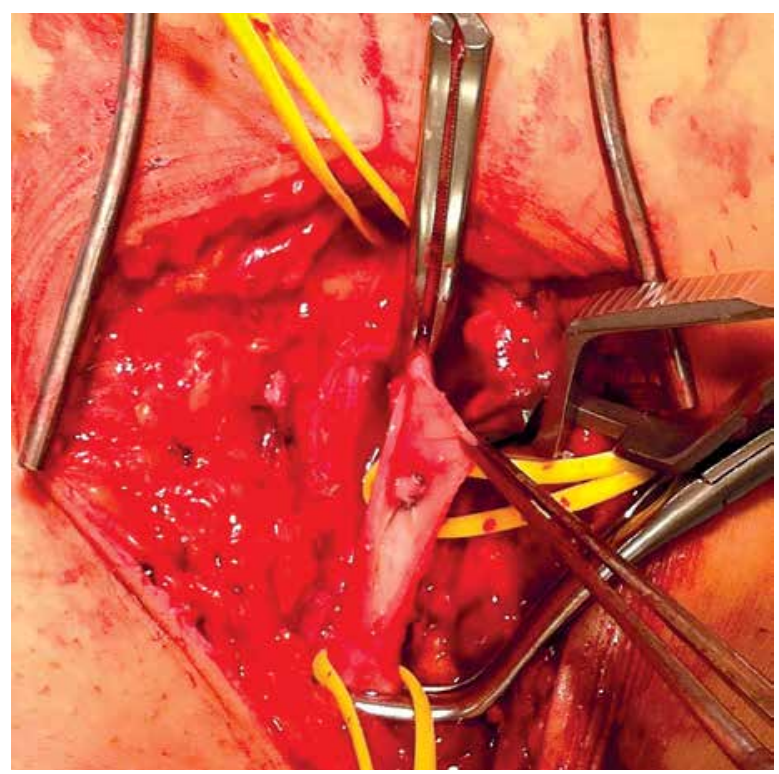

Photo 2. An intraoperative image showing the polyp-like structure on the posterior wall of the superficial femoral artery. The metallic clip is present at the base of the polyp 
ture was formed. At that time the observed failure of closure should have raised suspicion of incorrect deployment. The presence of an obstacle to blood flow together with the compression probably caused the thrombosis of origin of the superficial femoral artery. Because initially the patient was resting in the horizontal position the occlusion was asymptomatic. We hypothesize that the symptoms of severe acute limb ischemia developed when at the start of ambulation the thrombus was dislodged distally, occluding the popliteal artery with its trifurcation.

Several risk factors for vascular access site complication could be identified in the described patient: female sex, low body surface area and low body weight [4-7]. It has been shown that women have narrower arteries than men. Also a positive correlation between common femoral artery diameter and body surface area was reported [8]. In nonobese patients the superficial femoral artery is easily palpable and may be punctured more often than in obese patients.

It seems that this complication could have been avoided if ultrasound guidance had been used for arterial puncture. It has been shown that the use of ultrasound reduces the number of access site complications mainly by ensuring proper puncture localization in the common femoral artery $[9,10]$. At the time of the observed failure of closure, incorrect deployment should have been suspected, and the position of the nitinol Starclose clip could have been verified by ultrasound. It has been reported that the nitinol clip is easily visible in ultrasound [11]. Using duplex Doppler the obstruction and thrombosis would have also been identified, which would have enabled earlier intervention, avoiding the development of a potentially limb-threatening condition.

One solution to the similar problem as suggested by others could be an endovascular approach [12, 13]. In the present case an open approach was chosen because of the location and type of the lesion and because of the severity of acute limb ischemia. The type of occlusion would require a stent implantation, which we believed would not be the best option in a young patient with otherwise healthy arteries, especially at the bifurcation of the femoral artery. The occlusion of the popliteal artery and proximal portions of tibial arteries by a thrombus could have been resolved by catheter-directed thrombolysis. However, this treatment requires some time, and we feared that any delay in revascularization could lead to irreversible changes and limb loss. In previously reported cases of occlusive complications following the use of an arterial closure device that were solved by an endovascular approach, patients presented with intermittent claudication and stenosis of the femoral artery and not acute limb ischemia [12-14].

\section{Conclusions}

Arterial closure devices should be used with caution and within the instructions for use, since their incorrect use may lead to limb-threatening conditions. Proper supervision and training of young physicians is important.

\section{Conflict of interest}

The authors (Łukasz Dzieciuchowicz, Maciej Zmysłowski, Karolina Stefaniak) declare no conflict of interest.

\section{References}

1. Cox T, Blair L, Huntington C, et al. Systematic review of randomized controlled trials comparing manual compression to vascular closure devices for diagnostic and therapeutic arterial procedures. Surg Technol Int 2015; 27: 32-44.

2. Bangalore S, Arora N, Resnic FS. Vascular closure device failure: frequency and implications: a propensity-matched analysis. Circ Cardiovasc Interv 2009; 2: 549-56.

3. Rodriguez A, Katz SG. The use of the StarClose device for obtaining femoral artery hemostasis. Vasc Endovascular Surg 2011; 45: 627-30.

4. Piper WD, Malenka DJ, Ryan TJ Jr, et al.; Northern New England Cardiovascular Disease Study Group. Predicting vascular complications in percutaneous coronary interventions. Am Heart J 2003; 145: 1022-9.

5. Ahmed B, Piper WD, Malenka D, et al. Significantly improved vascular complications among women undergoing percutaneous coronary intervention: a report from the Northern New England Percutaneous Coronary Intervention Registry. Circ Cardiovasc Interv 2009; 2: 423-9.

6. Minutello RM, Chou ET, Hong MK, et al. Impact of body mass index on in-hospital outcomes following percutaneous coronary intervention (report from the New York State Angioplasty Registry). Am J Cardiol 2004; 93: 1229-32.

7. Ahmed B, Lischke S, De Sarno M, et al. Gender related differences in predictors of vascular complications: role of vessel size and BMI. J Thromb Thrombolysis 2013; 36: 84-90.

8. Schnyder G, Sawhney N, Whisenant B, et al. Common femoral artery anatomy is influenced by demographics and comorbidity: implications for cardiac and peripheral invasive studies. Catheter Cardiovasc Interv 2001; 53: 289-95.

9. Lo RC, Fokkema MT, Curran T, et al. Routine use of ultrasound-guided access reduces access site-related complications 
after lower extremity percutaneous revascularization. J Vasc Surg 2015; 61: 405-12.

10. Seto AH, Abu-Fadel MS, Sparling JM, et al. Real-time ultrasound guidance facilitates femoral arterial access and reduces vascular complications: FAUST (Femoral Arterial Access With Ultrasound Trial). JACC Cardiovasc Interv 2010; 3: 751-8.

11. Choo HJ, Jeong HW, Park JY, et al. Ultrasonographic features of vascular closure devices: initial and 6-month follow-up results. Ultrasonography 2014; 33: 283-90.

12. Rekik S, Brunet J, Bayet G, et al. Percutaneous management of lower limb ischemia after the use of vascular closure devices. Can J Cardiol 2013; 29: 1448-53.

13. Gemmete JJ, Dasika N, Forauer AR, et al. Successful angioplasty of a superficial femoral artery stenosis caused by a suture-mediated closure device. Cardiovasc Intervent Radiol 2003; 26 410-2.

14. Stefańczyk L, Elgalal MT, Szubert W, et al. Posterior wall capture and femoral artery stenosis following use of StarClose closing device: diagnosis and therapy. Cardiovasc Intervent Radiol 2013; 36: 1416-9.

Received: 1.12.2015, accepted: 7.03.2016. 